\title{
Ariane Charton, Alfred de Musset
}

\section{Valentina Ponzetto}

\section{(2) OpenEdition}

\section{Journals}

\section{Edizione digitale}

URL: http://journals.openedition.org/studifrancesi/6034

DOI: 10.4000/studifrancesi.6034

ISSN: 2421-5856

\section{Editore}

Rosenberg \& Sellier

\section{Edizione cartacea}

Data di pubblicazione: 1 mai 2011

Paginazione: 194

ISSN: 0039-2944

\section{Notizia bibliografica digitale}

Valentina Ponzetto, «Ariane Charton, Alfred de Musset», Studi Francesi [Online], 163 (LV | I) | 2011, online dal 30 novembre 2015, consultato il 13 janvier 2021. URL: http://journals.openedition.org/ studifrancesi/6034 ; DOI: https://doi.org/10.4000/studifrancesi.6034

Questo documento è stato generato automaticamente il 13 janvier 2021.

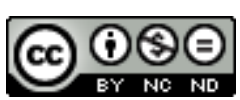

Studi Francesi è distribuita con Licenza Creative Commons Attribuzione - Non commerciale - Non opere derivate 4.0 Internazionale. 


\title{
Ariane Charton, Alfred de Musset
}

\author{
Valentina Ponzetto
}

\section{NOTIZIA}

ARIANE CHARTON, Alfred de Musset, Paris, Gallimard, «Folio biographies», 2010, pp. 323.

1 Il bicentenario della nascita di Alfred de Musset è l'occasione per molteplici iniziative editoriali, che vanno dall'edizione di testi alla pubblicazione di volumi collettivi e monografici. Fra questi non poteva mancare una biografia capace di avvicinare alle vicissitudini umane e private dell' "enfant du siècle» il lettore in cui questa messe di opere avesse risvegliato un nuovo o rinnovato interesse per l'autore senza tuttavia infondergli sufficiente motivazione per affrontare l'imponente e ricchissima biografia di Frank Lestringant (v. «Studi francesi», n 130, gennaio-aprile 2000).

2 Ariane Charton offre una biografia relativamente succinta ma completa e corretta, che seguendo un impianto rigorosamente cronologico, quasi annalistico, ripercorre la vita di Musset e il panorama delle sue opere, tutte rapidamente presentate al momento della loro composizione o pubblicazione. Pur senza grande originalità, la ricostruzione è tuttavia seria e accurata, e ha il pregio di lasciare spesso la parola in primis allo stesso Musset, attraverso ampi stralci delle sue opere più autobiografiche e della sua corrispondenza, quindi ai contemporanei: il fratello Paul, autore della prima e imprescindibile biografia dello scrittore, la fedele governante Adèle Colin, le donne amate, soprattutto quando autrici di un impareggiabile epistolario, come George Sand, o di vivide memorie, come Caroline Jaubert, gli amici e compagni di strada, come Sainte Beuve o Arsène Houssaye, e infine, sebbene in misura molto minore, qualche detrattore, come il perfido e irriverente poligrafo Eugène de Mirecourt.

Si può tuttavia rimpiangere da un lato che la bibliografia, assai nutrita per quanto riguarda l'Ottocento, sia per il Novecento più ridotta e soprattutto scarsamente aggiornata, componendosi essenzialmente di titoli risalenti a più di quarant'anni fa; dall'altro che le fonti d'epoca non siano sempre trattate con sufficiente distanza critica. Le citazioni dalla Confession d'un enfant du siècle o da Le Poète déchu, ad esempio, sono a 
tratti presentate sullo stesso piano della corrispondenza, laddove si tratta invece di opere di finzione, in cui l'elemento autobiografico è filtrato e rielaborato con intenti estetici e narrativi; e così pure le affermazioni di Paul de Musset, notoriamente tendenziose e «agiografiche», non sono sempre relativizzate come meriterebbero.

4 Sebbene privilegi nettamente, nella scelta delle fonti, gli amici ai detrattori di Musset, l'autrice ha tuttavia saputo mantenere un'apprezzabile imparzialità nei confronti dello scrittore, presentandolo con le sue luci e le sue ombre e in particolare disegnando un onesto quadro della sua precoce decadenza, senza falsi pudori o tentativi di idealizzazione come senza compiacimenti morbosi sui dettagli più sordidi.

Laddove Ariane Charton sembra invece meno imparziale è sul tema delle donne amate da Musset, uno dei soggetti su cui più si dilunga nel corso del volume. L'autrice non nasconde infatti una certa antipatia per Rachel, che a suo dire «n'était pas une femme de passion», «répondit mal à ces sentiments [quelli di Musset per lei] et ne comprit jamais l'écrivain» (p. 182), mentre mostra una netta predilezione per George Sand, tanto da cercarle ogni sorta di scusa e di attenuante al momento di render conto della famigerata avventura veneziana e della «liaison» con il dottor Pagello: «Sand ne voulait pas tant se venger des infidélités et de la légèreté du poète depuis leur arrivée à Venise que s'attacher un protecteur dans un pays étranger. Un protecteur qui lui faisait une cour pressante...» (p. 112).

Per quanto riguarda le opere, si sarebbe potuto desiderare una maggior contestualizzazione e un po' più di analisi contenutistica, mente la presentazione si riduce per lo più ad un semplice riassunto. Più grave è il fatto che tale presentazione non sia sempre esente da inesattezze, a meno che non si tratti di uno scrupolo di «bienséance» che avrebbe quanto meno di che sorprendere nel xxI secolo. Così a proposito dei capitoli della novella Emmeline che descrivono lo stato d'animo dell'eroina al momento di concedersi al suo amante è detto che Musset si rivolse a Caroline Jaubert «pour avoir quelques éclaircissements sur ce que ressent une femme à la veille et au lendemain de sa nuit de noces» (p. 164 - Nella sua lettera Musset parlava invero eufemisticamente di «noces d'amour», ma dopo aver detto inequivocabilmente «il s'agit $\mathrm{du}$ moment où une femme se donne ou se livre»). E ancora, il fallimento del progetto sadiano dell'abate Cassius, che sperando di raggiungere un godimento mai provato avvelena la sua vittima prima dell'amplesso e si ritrova insoddisfatto con un cadavere fra le braccia, viene riassunto con: «le soir du crime, Cassius trouve Suzon déjà morte et sombre dans la folie» (p. 71).

7 Apprezzabile e ben scelta è invece la breve rassegna stampa che rende conto della ricezione contemporanea delle «pièces» teatrali e di alcune raccolte poetiche. 